\title{
Morphological spectrum of endometrium with thyroid hormone profile in infertile female population of Khyber Pakhtunkhwa province of Pakistan
}

\author{
Sabeen Nasir ${ }^{1}$, Sara Ziaullah', \\ Sadaf Alam³, Muhammad Mumtaz Khan ${ }^{4}$
}

\section{ABSTRACT}

Objectives: To study the morphological spectrum of endometrial changes with the thyroid hormone levels in infertile women.

Methods: This cross sectional study was conducted at Department of Pathology, Peshawar Medical College, Health Care Centre and Madina Medical Laboratory, Peshawar from April 2013 to August 2013. Total 160 cases of infertile women were included in the study. Biopsies were taken on 22-23rd day of menstrual cycle. Statistical Analysis was performed using SPSS version 19 statistical program. Difference between endometrial findings of patients with normal thyroid profile and abnormal one were analyzed for statistical significance using Chi square test. Probability values $p \leq 0.05$ were considered statistically significant.

Results: In our study, majority infertile women were euthyroid $(80 \%)$, followed by hyperthyroid (18\%) and only two\% to be hypothyroid. The correlation of endometrial morphology with thyroid hormones levels turned out to be insignificant. While correlating histological details of endometrial biopsy with thyroid hormone status, we found significant association of leukocytic infiltrate with thyroid hormone levels.

Conclusion: This study shows that thyroid hormones may have role in early leukocytic infiltration into stroma, and a possibility of immune modulation by altered thyroid hormones in causing infertility.

KEYWORDS: Endometrium, Infertility, Thyroid hormones.

doi: https://doi.org/10.12669/pjms.36.5.1791

How to cite this:

Nasir S, Ziaullah S, Alam S, Khan MM. Morphological spectrum of endometrium with thyroid hormone profile in infertile female population of Khyber Pakhtunkhwa province of Pakistan. Pak J Med Sci. 2020;36(5):904-908. doi: https://doi.org/10.12669/pjms.36.5.1791

This is an Open Access article distributed under the terms of the Creative Commons Attribution License (http://creativecommons.org/licenses/by/3.0), which permits unrestricted use, distribution, and reproduction in any medium, provided the original work is properly cited.

1. Dr. Sabeen Nasir, MBBS, M. Phil.

2. Dr. Sara Ziaullah, MBBS, M. Phil. Associate Professor,

3. Dr. Sadaf Alam, MBBS, M. Phil. Associate Professor,

4. Dr. Muhammad Mumtaz Khan, MBBS, M. Phil.

1-4: Department of Pathology,

Peshawar Medical College, Peshawar, Pakistan.

Correspondence:

Dr. Sara Ziaullah, Assistant Professor, Department of Pathology, Peshawar Medical College, Peshawar, Pakistan. Email: drsarazia@gmail.com

* Received for Publication:

* $1^{\text {st }}$ Revision Received:

* $2^{\text {nd }}$ Revision Received:

* Final Revision Accepted:
October 8, 2019

October 26, 2019

March 12, 2020

May 18,2020

\section{INTRODUCTION}

Infertility is a growing problem affecting $8-12 \%$ couples of reproductive age group. ${ }^{1}$ It is defined as the failure to establish a clinical pregnancy after 12 months of regular and unprotected sexual intercourse. Primary infertility refers to a condition in which a woman has never been diagnosed with a clinical pregnancy, while in secondary infertility, a woman is unable to establish a clinical pregnancy after previously been diagnosed with a clinical pregnancy. ${ }^{2}$

There are certain obstacles in true estimation of prevalence of infertility i.e. lack of consensus on definition, uniform tools for diagnosis, underreporting of infertile individual and couples. However, the available data shows that prevalence 
of infertility differs among various geographical regions. It also varies from country to country and from region to region within the same country. ${ }^{3}$ In developed countries the prevalence of infertility ranges between four percent to $16.7 \%$. In less developed countries percentage ranges between seven percent to nine percent. ${ }^{4}$ The global prevalence of primary infertility is $2 \%$, while that of secondary infertility it is about $10.5 \% .{ }^{3}$ Pakistan is located in South Asia which is high infertility prevalence region. ${ }^{5}$ In Pakistan, the estimated prevalence of infertility is $21.9 \%$, of which primary infertility is four percent and secondary infertility is $18.4 \%{ }^{6}$

There are many causes of infertility in females. They can be broadly classified as anatomical and hormonal. Anatomical causes include tubal blockage (14-15\%), uterine (16-17\%) and cervical $(15 \%)$ causes. $^{7}$

Hormonal abnormalities contribute to infertility in women. Besides the hormones of hypothalamicpituitary-gonadal axis, which mainly regulates the reproductive system, role of thyroid hormones and prolactin cannot be overlooked. Abnormal thyroid hormone/prolactin levels may cause menstrual disturbances, which can lead to female infertility. ${ }^{8,9}$ Thyroid hormone receptors are also found in both endometrial glands and stroma. ${ }^{10}$ This further supports the idea that thyroid hormone may have role in bringing out morphological changes in endometrium, necessary for establishment of pregnancy. The prevalence of abnormal thyroid hormones levels in infertile women is variable globally. Hyperthyroidism in such women ranges from $2 \%$ to $5 \%$ while hypothyroidism in infertile women ranges from $2 \%$ to $8 \% .8,11,12$

Human endometrium is a steroid hormone responsive tissue, whose cellular components respond to cyclic changes in circulating ovarian derived estradiol and progesterone. The endometrium undergoes precisely defined morphological changes until a receptive endometrium is developed. ${ }^{13}$ Different morphologic patterns of endometrium usually associated with infertility include disordered proliferative endometrium, hyperplasia, luteal phase defect and endometritis. ${ }^{14}$

Much work has been done regarding morphological changes in endometrium with steroid hormone dysfunctions. However, studies correlating morphological changes in endometrium with thyroid hormone disorders are lacking. Morphological spectrum in response to changes in thyroid profile have been studied in experimental animals, ${ }^{15,16}$ however no such work has been carried out in infertile women specifically in our setup. Therefore, the objective of our study was to observe the effects of blood thyroid levels on endometrial morphology of infertile women with an aim to rule out thyroid abnormalities as a cause of infertility.

\section{METHODS}

This cross sectional study was conducted at Department of Pathology Peshawar Medical College, Health Care Centre and Madina Medical Laboratory and Diagnostic Center Peshawar from April 2013 to August 2013. After approval by Institutional Review Board (Ref No. Prime/ IRB/2019-188) 160 cases of infertile women were recruited. Those females with normal laparoscopic findings and normal semen analysis of their spouse were included in the study through consecutive sampling. Females with organic lesions on laparoscopy were excluded from study. Blood samples for thyroid function tests were obtained and biopsies were taken on 22-23rd day of menstrual cycle and Hematoxylin \& Eosin (H\&E) stained slides were examined under light microscope. Endometrial biopsies showing secretory phase were considered normal. Estimation of serum levels of thyroid hormones (TSH, T3 and T4) were performed on Chemiluminescence Immunoassay Analyzer CLIA-IIS manufactured by Biomed Engineering, China. The reference values for thyroid hormones status were taken as TSH ( 0.35 to $5.3 \mu \mathrm{lU} / \mathrm{mL}), \mathrm{T} 4$ (5.0 to $13.0 \mu \mathrm{g} / \mathrm{dL}$ ), T3 (0.8 to $1.9 \mathrm{ng} / \mathrm{mL}$ ). Values below/above were considered abnormal.

Statistical analysis: It was performed using SPSS version 19 statistical program. Statistical results were presented as mean and standard deviation for continuous variables. Difference between endometrial findings of patients with normal thyroid profile and abnormal one were analyzed for statistical significance using Chi square test. Probability values $\mathrm{p} \leq 0.05$ were considered statistically significant.

\section{RESULTS}

This study consisted of 160 infertile women of reproductive age group. Out of these cases, 102 $(63.75 \%)$ belonged to primary infertility group. Fifty-eight $(36.25 \%)$ cases had secondary infertility. Majority of women $(80 \%)$ had normal thyroid profile. Among those with abnormal thyroid profile, $29(18 \%)$ patients were hyperthyroid and only $3(2 \%)$ patients turned out to be hypothyroid. The age range was from 16-42 years with a mean age of 28.13 years $(S D \pm 5.11)$. 
Sabeen Nasir et al.

Table-I: Morphological patterns of endometrium in Infertile women with Thyroid Hormone Status.

\begin{tabular}{|c|c|c|c|c|c|c|c|}
\hline \multirow{3}{*}{$\begin{array}{l}\text { Sr. } \\
\text { No. }\end{array}$} & \multirow{3}{*}{$\begin{array}{l}\text { Endometrial Morphology } \\
\qquad(N=157)\end{array}$} & \multicolumn{4}{|c|}{ Serum Thyroid Hormone Status } & \multirow{3}{*}{$\begin{array}{l}\text { Value of } \\
\text { Chi square }\end{array}$} & \multirow[t]{3}{*}{$p$-Value } \\
\hline & & \multicolumn{2}{|c|}{ Euthyroid } & \multicolumn{2}{|c|}{ Hyperthyroid } & & \\
\hline & & $\%$ & $n$ & $\%$ & $n$ & & \\
\hline 1. & Secretory Phase $(n=101)$ & 79 & 80 & 21 & 21 & 0.627 & 0.42 \\
\hline 2. & Proliferative Phase $(n=08)$ & 75 & 6 & 25 & 2 & 0.07 & 0.76 \\
\hline 3. & Irregular Maturation $(n=12)$ & 83 & 10 & 17 & 2 & 0.11 & 0.73 \\
\hline 4. & Disordered Proliferative $(n=27)$ & 93 & 25 & 7 & 2 & 2.58 & 0.10 \\
\hline 5. & Simple Hyperplasia $(n=03)$ & 67 & 2 & 33 & 1 & 1.91 & 0.16 \\
\hline 6. & Complex Hyperplasia $(n=06)$ & 83 & 5 & 17 & 1 & 0.05 & 0.8 \\
\hline
\end{tabular}

The endometrial findings in euthyroid and hyperthyroid patients are shown in Tables-I-II. While calculating p-value, we considered only hyperthyroid patients versus euthyroid patients, because hypothyroidism was found only in three patients.

Morphological patterns of endometrium in infertile women with Thyroid Hormone status is shown in Table-I. The endometrial biopsy of 101 patients (64.33\%) showed secretory phase, which is a normal finding at $22^{\text {nd }} / 23^{\text {rd }}$ day of menstrual cycle. The second major group was of disordered proliferative endometrium comprising of 27 patients, followed by irregular maturation of endometrium. The correlation of endometrial morphological patterns with serum thyroid hormones levels turned out to be insignificant.

Histological details of endometrial biopsy and its correlation with thyroid hormone status are shown in Table-II. The parameters that we considered included shape of the glands and type of their lining epithelia. The stromal details included stromal edema, decidualization, leukocytic infiltrate and thickness of spiral arterioles. Only association of leukocytic infiltrate to thyroid hormone levels was significant.

\section{DISCUSSION}

For implantation of embryo and establishment of pregnancy, properly formed endometrial bed is mandatory. The required morphological changes are carried out by ovarian steroid hormones, estrogen and progesterone. ${ }^{17}$ However, as a general metabolic hormone the possible action of thyroid hormone in bringing different morphological changes at various phases of endometrial development cannot be ignored..$^{18}$

Table-II: Histological details of endometrial biopsy and its correlation with thyroid hormone status.

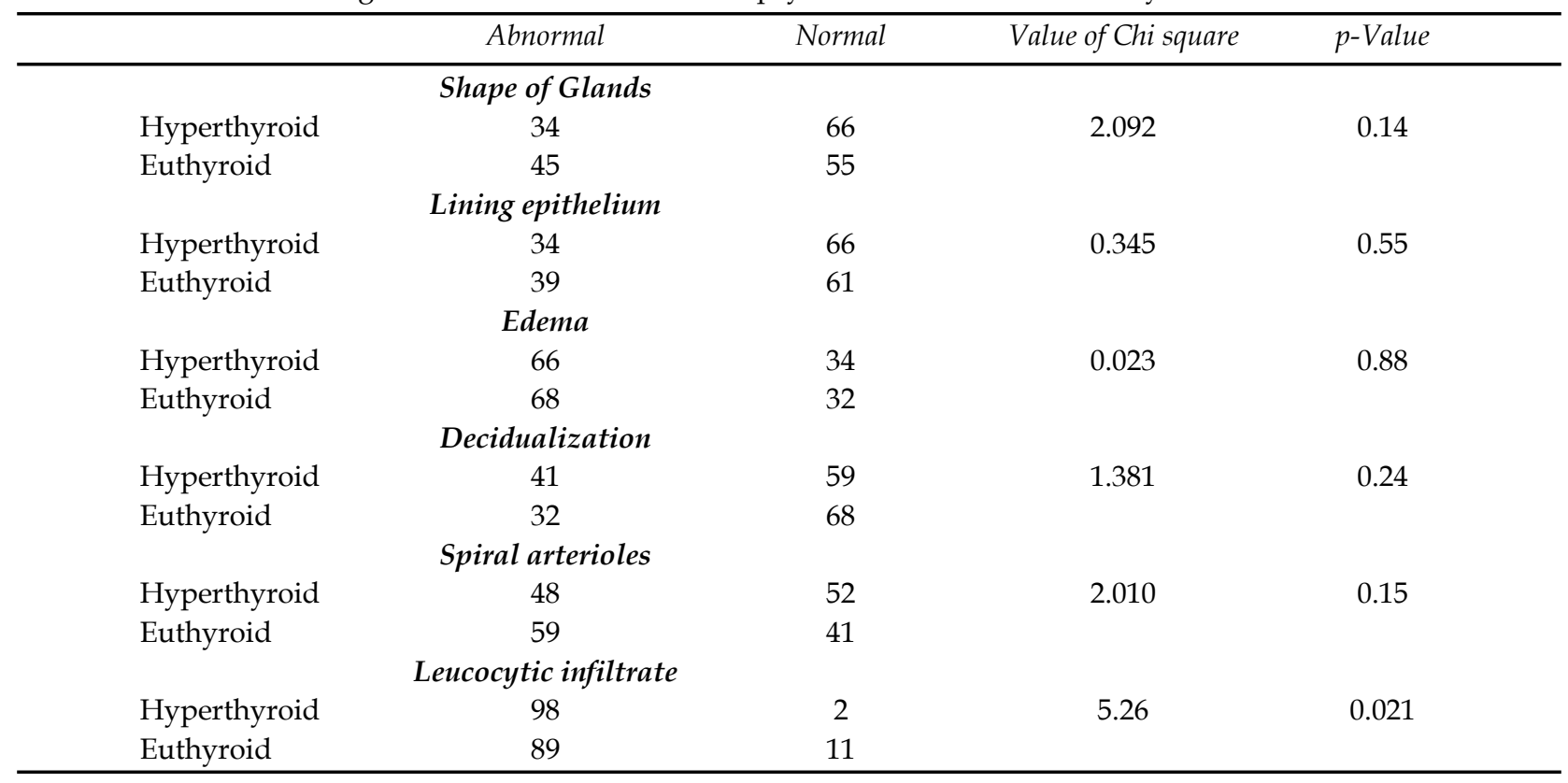


Some local and foreign workers have published articles on relationship of altered thyroid hormone levels with infertility, but they lack in relating it to associated morphological changes in endometrium. ${ }^{19-22}$ Another group of authors considered morphological changes in endometrium of infertile women, without taking in account the thyroid hormone status of patients. ${ }^{23,24}$ However, such studies on animal subjects are present; they focus histological changes in endometrium only. ${ }^{15,16}$ Our study is unique in considering morphological patterns along with histological changes in endometrium.

The thyroid hormone levels of majority of infertile females in our study are within normal range $(80 \%)$. These results are similar to the studies done in Peshawar and Faisalabad which show 94\% and $62.2 \%$ of infertile women to be euthyroid. ${ }^{19,25}$ Likewise, studies done in India and Nepal show $75 \%$ of infertile patients were euthyroid. ${ }^{12,26}$ The frequency of hyperthyroid patients in our study is $18 \%$ while hypothyroid patients constitute only $2 \%$ of patients. This may not be surprising as hyperthyroidism is more prevalent in our region as compared to hypothyroidism. ${ }^{27,28}$ These findings also correlate with study done in Pakistan by Lalani $\mathrm{S}$ and in India by Kameswaramma $\mathrm{K}$ et al., while studies done in Nepal by Rijal B et al. and in Pakistan by Naib et al. shows high prevalence of hypothyroidism as compared to hyperthyroidism in infertile women. ${ }^{12,19,29,30}$

In our study we found that in majority of infertile women $(64 \%)$, the morphological pattern of endometrium (secretory phase) coincides with dates, irrespective of thyroid hormone status. In remaining females $(36 \%)$ the endometrium shows a variety of changes, including disordered proliferative endometrium, hyperplasia, irregular maturation etc. There was no significant difference between hyperthyroid and euthyroid groups. We couldn't find any other study relating morphological changes in human endometrium with thyroid hormone derangements in infertility. ${ }^{31}$ However, there are studies available which can explain the reason for our findings. For example, some studies reveal that thyroid hormone may be synthesized locally in endometrial tissue and act in a paracrine fashion. ${ }^{10,32}$ In addition gonadal steroids can also modulate expression of thyroid hormone receptors in endometrium..$^{33}$ Because of multiple mechanisms involved in thyroid hormones actions, it is not necessary that serum hormone levels may always be predictive of its availability and activity at cellular levels. ${ }^{34}$
Regarding histological details, we compared our findings with studies on animals, because no human study is present so far. According to our study, p-value is only significant for leukocytic infiltrate in endometrial stroma. This is in contrast to study done on rats by Lutsyk and Sogomonian which revealed heavy leucocyte infiltration of the endometrial stroma in hypothyroidism. ${ }^{15}$ However, some studies show that hyperthyroidism induce leucocytic proliferation..$^{35}$

\section{CONCLUSION}

This study shows that thyroid hormones may have role in early leukocytic infiltration into stroma, and a possibility of immune modulation by altered thyroid hormones in causing infertility.

Recommendations: Further studies are recommended to find any possible role of thyroid hormones on endometrium at subcellular levels in infertile females. In addition, studies relating to the possible role of thyroid antibodies in causing infertility should be done.

Acknowledgement: We are thankful to Prof. Dr. Sajjad Ahmad, Head, Department of Pathology, Peshawar Medical College for his continuous support during the project. We also acknowledge Dr. Hina khan for reviewing and editing manuscript.

Conflict of interests: None.

Grant Support \& Financial Disclosures: None.

\section{REFERENCES}

1. Borght VM, Wyns C. Fertility and infertility: Definition and epidemiology. Clin Biochem. 2018;62:2-10. doi: 10.1016/j. clinbiochem.2018.03.012

2. Hochschild ZF, Adamson GD, Dyer S, Racowsky C, de Mouzon J, Sokol R, et al. The International Glossary on Infertility and Fertility Care, 2017. Fertil Steril. 2017;108(3):393-406. doi: 10.1016/j. fertnstert.2017.06.005

3. Mascarenhas MN, Flaxman SR, Boerma T, Vanderpoel S, Stevens GA. National, Regional, and Global Trends in Infertility Prevalence Since 1990: A systematic analysis of 277 Health Surveys. PLoS Med. 2012;9(12):e1001356. doi: 10.1371/journal.pmed.1001356

4. Boivin J, Bunting L, Collins JA, Nygren KG. International estimates of infertility prevalence and treatment-seeking: potential need and demand for infertility medical care. Human Reprod. 2007;22(6):1506-1512. doi: 10.1093/ humrep/dem046

5. Inhorn MC, Patrizio P. Infertility around the globe: new thinking on gender, reproductive technologies and global movements in the 21st century. Human Reprod Update. 2015;21(4):411-426. doi: 10.1093/ humupd/dmv016 
6. Ali S, Sophie R, Imam AM, Khan FI, Ali SF, Shaikh A, et al. Knowledge, perceptions and myths regarding infertility among selected adult population in Pakistan: a crosssectional study. BMC Public Health. 2011;11(1):760. doi: 10.1186/1471-2458-11-760

7. Masoumi SZ, Parsa P, Darvish N, Mokhtari S, Yavangi M, Roshanaei G. An epidemiologic survey on the causes of infertility in patients referred to infertility center in Fatemieh Hospital in Hamadan. Iranian J Reprod Med. 2015;13(8):513-516.

8. Goswami B, Patel S, Chatterjee M, Koner B, Saxena A. Correlation of Prolactin and Thyroid Hormone Concentration with Menstrual Patterns in Infertile Women. J Reprod Infertil. 2009;10(3):207-212.

9. Unuane D, Tournaye H, Velkeniers B, Poppe K. Endocrine disorders \& female infertility. Best Pract Res Clin Endocrinol Metabol. 2011;25(6):861-873. doi: 10.1016/j.beem.2011.08.001

10. Aghajanova L, Evers SA, Lindeberg M, Landgren B-M, Sparre LS, Hovatta O. Thyroid-stimulating hormone receptor and thyroid hormone receptors are involved in human endometrial physiology. Fertil Steril. 2011;95(1):230237.e2. doi: 10.1016/j.fertnstert.2010.06.079

11. Jefferys A, Vanderpump M, Yasmin E. Thyroid dysfunction and reproductive health. Obstet Gynaecol. 2015;17(1):39-45. doi: $10.1111 /$ tog. 12161

12. Rijal B, Shrestha R, Jha B. Association of thyroid dysfunction among infertile women visiting infertility center of Om Hospital, Kathmandu, Nepal. Nepal Med Coll J. 2011;13(4):247-249.

13. Deligdisch L. Hormonal Pathology of the Endometrium. Modern Pathol. 2000;13:285.

14. Nandedkar SS, Patidar E, Gada DB, Malukani K, Munjal K, Varma A. Histomorphological Patterns of Endometrium in Infertility. J Obstet Gynaecol India. 2015;65(5):328-334. doi: 10.1007/s13224-014-0614-4

15. Lutsyk A, Sogomonian E. Structural, functional, and lectin histochemicalcharacteristics of rat ovaries and endometrium in experimental hyper- and hypothyroidism. Folia Histochem Cytobiol. 2012;50(3):331-339. doi: 10.5603/19742

16. Sarkar D, Chakraborty A, Mahapatra D, Chandra AK. Morphological and functional alterations of female reproduction after regular exposure of bamboo shoots of North East India. Asian Pacific J Reprod. 2017;6(4):151-157. doi: 10.12980/apjr.6.20170402

17. Wang X, Wu SP, DeMayo FJ. Hormone dependent uterine epithelial-stromal communication for pregnancy support. Placenta. 2017;60(Suppl 1):S20-S26. doi: 10.1016/j. placenta.2017.07.003

18. Kong L, Wei Q, Fedail JS, Shi F, Nagaoka K, Watanabe G. Effects of thyroid hormones on the antioxidative status in the uterus of young adult rats. J Reprod Dev. 2015;61(3):219227. doi: $10.1262 /$ jrd.2014-129

19. Naib JM, Fatima SS, Naz T, Khan EH. Frequency of TSH derangement in subfertility workup. J Med Sci. 2014;22(4):182-184.

20. Ain NU, Rehman HA, Abdullah. Correlation of Prolactin and Thyroid Hormone Levels in Infertile Women: A CrossSectional Study in Pakistan. J Clin Exp Pathol. 2017;7(1):304. doi: 10.4172/2161-0681.1000304

21. Shrestha S, Neupane S, Gautam N, Dubey RK, Jha AC, Doshi NR, et al. Association of Thyroid Profile and Prolactin Level in Patient with Secondary Amenorrhea. Malaysian J Med Sci. 2016;23(5):51-56. doi: 10.21315/mjms2016.23.5.7

22. Bassey IE, Udoh AE, Essien O, Isong IKP, Gali RM, Archibong EE. Thyroid Hormones and Prolactin Levels in Infertile Women in Southern Nigeria. J Clin Diagn Res. 2015;9(3):13-15. doi: 10.7860/JCDR/2015/11505.5659
23. Pradhan SP, Dash A, Choudhury S, Mishra DP. A study on endometrial morphology and glycogen content In Infertile women. J Evid Based Med Healthcare. 2017;4(9):528-532. doi: $10.18410 /$ jebmh/2017/100

24. Girish CJ, Manjunath ML. Morphological Patterns of Endometrium in Infertile Woman-a Prospective Study. Int J Applied Biol Pharm Tech. 2011;2(3):512-520.

25. Rahman R, Saeed M, Zia S, Jan F, Muzaffar S, Waheed A. Prevalence of thyroid disorders in primary infertile women of reproductive age. Prof Med J. 2019;26(1):101-108.

26. Pushpagiri N, Gracelyn LJ, Nagalingam S. Prevalence of subclinical and overt hypothyroidism in infertile women. Int J Reprod Contracept Obstet Gynecol. 2015;4(6):17331738. doi: 10.18203/2320-1770.ijrcog20151214

27. Attaullah S, Haq BS, Muska M. Thyroid dysfunction in Khyber Pakhtunkhwa, Pakistan. Pak J Med Sci. 2016;32(1):111-115. doi: 10.12669/pjms.321.8476

28. Shah SIA, Muhammad S, Sharif N, Shah F. Frequency of Subclinical Hyper and Hypothyroidism. Int J Pathol. 2018;16(2):64-68.

29. Kameswaramma K. Study of correlation of thyroid profile and clinical parameters in patients with infertility. Int J Reprod Contraception Obstet Gynecol. 2016;5(5):1410-1413. doi: 10.18203/2320-1770.ijrcog20161295

30. Lalani S, Nizami I, Hashmi AA, Saifuddin A, Rehman R. Throid Dysfunction and Infertility Treatment. Acta Endocrinologica. 2017;13(3):302-307. doi: 10.4183/ aeb.2017.302

31. Vissenberg R, Manders VD, Mastenbroek S, Fliers E, Afink GB, Ris-Stalpers C, et al. Pathophysiological aspects of thyroid hormone disorders/thyroid peroxidase autoantibodies and reproduction. Human Reprod Update. 2015;21(3):378-387. doi: 10.1093/humupd/dmv004

32. Stavreus Evers A. Paracrine interactions of thyroid hormones and thyroid stimulation hormone in the female reproductive tract have an impact on female fertility. Front Endocrinol. 2012;3:50. doi: 10.3389/fendo.2012.00050

33. Sayem ASM, Giribabu N, Karim K, Si LK, Muniandy $\mathrm{S}$, Salleh N. Differential expression of the receptors for thyroid hormone, thyroid stimulating hormone, vitamin $\mathrm{D}$ and retinoic acid and extracellular signal-regulated kinase in uterus of rats under influence of sex-steroids. Biomed Pharmacother. 2018;100:132-141. doi: 10.1016/j. biopha.2018.02.008

34. Colicchia M, Campagnolo L, Baldini E, Ulisse S, Valensise $\mathrm{H}$, Moretti C. Molecular basis of thyrotropin and thyroid hormone action during implantation and early development. Human Reprod Update. 2014;20(6):884-904. doi: 10.1093/ humupd/dmu028

35. Vito DP, Incerpi S, Pedersen JZ, Luly P, Davis FB, Davis PJ. Thyroid hormones as modulators of immune activities at the cellular level. Thyroid. 2011;21(8):879-890. doi: 10.1089/ thy.2010.0429

\section{Author`s Contribution:}

SN conceived, designed and did data collection \& editing of manuscript. Responsible and accountable for the accuracy or integrity of the work.

SZ did statistical analysis and manuscript writing. SA did review and editing of manuscript. MMK did review and final approval of manuscript. 